\section{СОСТАВЛЯЮЩИЕ ПРАВА НА ЖИЗНЬ: ДОКТРИНАЛЬНЫЕ ПОДХОДЫ И ТРАКТОВКА В СУДЕБНЫХ РЕШЕНИЯХ}

Аннотация:

В статье рассмотрены основные подходы к компонентам права на жизнь таких авторов, как Г.Б. Романовский, О.Е. Кутафин, Н.В. Кальченко, В.М. Танаев. Подробно изучены следующие права: на средства к существованию, здравоохранение, охрану здоровья, образование, благоприятную окружающую среду, а также положительная обязанность государства по обеспечению условий, гарантирующих достойный уровень жизни. Проведен анализ некоторых дел Европейского суда по правам человека (Пентиакова и др. против Молдовы, Осман против Соединенного Королевства), Межамериканского суда по правам человека (Виллагран-Моралес и другие против Гватемалы, Якьи Акса против Парагвая), Верховного суда Индии (Пашим Банга Кхет Маздур Самити и др. против Западной Бенгалии, Мохини Джане против Карнатака, Унни Кришнан против Индии), Верховного суда Пакистана (Шела Зия против Водного хозяйства и развития энергетики), посвященных составляющим права на жизнь.

\section{Ключевые слова:}

права человека, право на жизнь, право на здравоохранение, право на образование, право на благоприятную окружающую среду, право на средства к существованию, международные стандарты прав человека, Европейский суд по правам человека, Межамериканский суд по правам человека, Верховный суд Индии, Верховный суд Пакистана.

\section{THE COMPONENTS OF THE RIGHT TO LIFE: DOCTRINAL APPROACHES AND INTERPRETATION IN JUDICIAL DECISIONS}

Summary:

The article describes the main approaches to the components of the right to life of such authors as G.B. Romanovsky, O.E. Kutafin, N.V. Kalchenko, V.M. Tanaev. The following rights are considered in detail: the right to livelihood, the right to health care, the right to health protection, the right to education, the right to a favourable environment. Besides, the study reviews the positive duty of the state to ensure conditions that guarantee a decent standard of living. The author analyses several cases of the European Court of Human Rights (Pentiacova and Others v. Moldova, Osman v. United Kingdom), the InterAmerican Court of Human Rights (Villagran-Morales and Others v. Guatemala, Yakye Axa v. Paraguay), the Supreme Court of India (Paschim Banga Khet Mazdoor Samity \& Others v. State of West Bengal, Mohini Jain v. State of Karnataka, Unni Krishnan v. India), the Supreme Court of Pakistan (Shehla Zia v. the Water and Power Development Authority (WAPDA)) concerning the components of the right to life.

Keywords: human rights, right to life, right to health care, right to education, right to a favourable environment, right to livelihood, international human rights standards, European Court of Human Rights, the Inter-American Court of Human Rights, Supreme Court of India, Supreme Court of Pakistan.

Институт законодательства и сравнительного правоведения при разработке Конституции Российской Федерации определил: «Право на жизнь - это основной аргумент граждан в их требованиях по охране среды и против акций, угрожающих их здоровью и жизни» [1]. Таким образом, составители Конституции РФ помимо гарантий права защиты от посягательства других людей и вопроса смертной казни выделяли одну из составляющих права на жизнь: право на безопасную окружающую среду, экологическую и ядерную безопасность.

Прежде чем перейти к судебной трактовке данного права, представляется необходимым выделить основные доктринальные подходы к его составляющим. Рассматривая структуру права на жизнь, Г.Б. Романовский анализирует четыре ее элемента: право-поведение, право-требование, право-пользование и право-притязание [2]. По мнению М.Н. Малеиной, право на жизнь состоит из правомочий на сохранение жизни (индивидуальности) и распоряжение жизнью [3]. На наш взгляд, структура в чем-то сходна с правом собственности (триадой прав - владения, пользования и распоряжения).

Нельзя не согласиться с О.Е. Кутафиным, считающим, что «основной составляющей права на жизнь является неприкосновенность жизни, которая охраняется государством» [4]. В.М. Танаев формирует право на жизнь из трех блоков: собственно право на жизнь, право на риск и право на прекращение жизни. Собственно право на жизнь включает в себя право на охрану здоровья и медицинскую помощь, право на благоприятную окружающую среду, право на достаточный жизненный уровень и право на защиту жизни [5]. Полагаем, что право на прекращение жизни, а именно право на смерть, не может являться составляющей по той причине, что смерть есть отсутствие жизни. 
Н.В. Кальченко также выделяет заслуживающую интереса составляющую - правомочия по спасению жизни. Скорее всего, к данному компоненту можно отнести меры государства по оказанию своевременной медицинской помощи (в том числе оперативному медицинскому вмешательству), а также комплекс активных действий по созданию и поддержанию безопасной окружающей среды, условий жизни [6].

Несмотря на многочисленность подходов, многие авторы выделяют аналогичные составляющие права на жизнь, такие как права на безопасную окружающую среду, достаточный жизненный уровень, охрану здоровья. В связи с этим интересной представляется практика Европейского суда по правам человека, Межамериканского суда по правам человека, Верховного суда Индии, Верховного суда Пакистана, отражающая следующие компоненты права на жизнь.

1. Положительная обязанность государства по обеспечению условий, гарантирующих достойный уровень жизни. В деле Виллагран-Моралес и другие против Гватемалы Межамериканский суд по правам человека пояснил: «Право на жизнь является основным правом человека, и осуществление этого права важно для реализации всех других прав человека. Если государство не защищает данное право, то значение всех других прав теряется» [7]. В сущности основное право на жизнь включает следующие элементы:

- право человека не быть произвольно лишенным жизни;

- право на беспрепятственный доступ к условиям, которые гарантируют достойное существование.

В деле Осман против Соединенного Королевства 28.10.1998 г. Европейский суд по правам человека указал, что позитивное обязательство государства принимать превентивные меры для защиты определенного лица или лиц возникает, в частности, в тех случаях, когда власти знали или должны были знать о наличии «реальной и непосредственной опасности для жизни определенного лица или лиц в связи с преступными действиями третьих лиц» [8].

Исходя из практики Европейского суда по правам человека, позитивные обязательства включают следующие элементы:

1) обязательство устанавливать правовые нормы, в том числе эффективные уголовные законы и процедуры; стандарты доказывания, необходимые для установления ответственности государства за незаконное лишение жизни;

2) обязательство привлекать виновных за незаконное лишение жизни;

3) обязательство защищать лиц, чья жизнь находится под угрозой: обращающихся к властям с просьбой обеспечить им защиту; страдающих вследствие загрязнения окружающей среды; находящихся на грани самоубийства или убийства со стороны третьих лиц в заключении.

Безусловно, к положительной обязанности государств можно отнести политику и программы, направленные на увеличение благосостояния общества.

2. Право на здравоохранение. Само по себе оно является всеобъемлющим, так как включает право на безопасную питьевую воду, здоровую окружающую среду и медицинскую помощь. В деле Пашим Банга Кхет Маздур Самити и др. против Западной Бенгалии Верховный суд Индии посчитал, что право на неотложную медицинскую помощь было реализовано в соответствии со ст. 21 Конституции Индии [9]. Суд исходил из того, что право на неотложную медицинскую помощь является основным компонентом права на здоровье, которое в свою очередь выступает главной частью права на жизнь. Статья 21 Конституции Индии гласит: «Никто не должен быть лишен жизни или личной свободы, кроме случаев, предусмотренных согласно порядку, установленному законом» [10].

Например, в деле Пентиакова и другие против Молдовы от 04.01.2005 г. речь шла о хронической почечной недостаточности заявителей, которым требовался гемодиализ [11]. По мнению заявителей, которые ссылаются на случай Г. Лунгу, в последние годы скончался ряд пациентов по причине отсутствия того или иного препарата или надлежащей медицинской помощи. Однако доказательства приведены не были. Европейский суд по правам человека отметил, что хроническая почечная недостаточность является очень серьезным прогрессирующим заболеванием с высоким уровнем смертности не только в Молдове, но и во всем мире. Поэтому сам факт смерти человека от этого заболевания не означает, что она была связана с недостатками в системе медицинского обслуживания. С учетом этого данная жалоба была признана явно необоснованной.

Государства, как правило, обеспечивают медицинскую помощь всему населению. При этом суд предоставляет властям широкие дискреционные полномочия в тех случаях, когда речь идет о распределении ограниченных бюджетных ресурсов в данной области, и поэтому не проявляет желания вмешиваться в решение этих вопросов и оценивать качество подобной помощи.

Этот компонент права на жизнь налагает обязанность на государство предоставлять доступные средства здравоохранения, а также устранять ситуации, неблагоприятные для здоровья 
граждан. Право на жизнь должно охраняться государством, даже когда люди изолированы географически или в фринансовом отношении, а доступ к медицинским услугам, безопасной питьевой воде ограничен.

3. Право на средства к существованию. Верховный суд Индии также определил право на жизнь, включая в его структуру право на средства к существованию. В деле Мохини Джане против Карнатака истец в заявлении просил определить конституционность сбора, взимаемого с тех, кто хотел бы поступить в медицинскую школу [12]. В частности, бедная семья не могла внести обозначенную сумму. Суд опирался на ст. 21 Конституции Индии, чтобы объявить рассматриваемый сбор неконституционным. Суд заявил: «Мы считаем, что право на жизнь включает право на достойное существование и все, что с ним связано, а именно: адекватное питание, одежду и жилье, а также возможности для чтения, письма».

Аналогичные рассуждения были изложены Межамериканским судом по правам человека в деле Якьи Акса против Парагвая [13]. Суд постановил, что необеспечение доступа заявителя к средствам для существования является нарушением права на жизнь в соответствии со ст. 4 Межамериканской конвенции о правах человека. Согласно данному документу, «каждый человек имеет право на уважение своей жизни». Аргументация того же суда в деле Street Children выражается следующим образом: «Доступ к условиям, гарантирующим достойное существование, является частью права на жизнь, которое следует рассматривать в свете доступа к средствам к существованию» [14].

4. Право на образование. В деле Унни Кришнан против Индии Верховный суд Индии определил характер прав, содержащихся в ст. 45 Конституции Индии [15]. Документ предусматривает, что «государство будет стремиться обеспечить в течение 10 лет с момента вступления в силу настоящей Конституции свободный и обязательный характер образования для всех детей до достижения 14 лет». Суд постановил, что срок в 44 года со дня вступления в силу Конституции фактически превратил не подлежащее судебной защите право на образование детей в возрасте до 14 лет в подлежащее исполнению. Далее суд исходил из того, что право на образование имеет основополагающее значение для осуществления права на жизнь в соответствии со ст. 21 Конституции Индии 1950 г. [16]. Соответственно, гражданин имеет право на образование в пределах его экономического потенциала и развития. Действительная связь между правом на жизнь и образованием становится очевидной, если рассматривать его в свете того факта, что необразованному индивидууму без опыта трудовой деятельности трудно найти работу. В итоге человек не только останется с пониженной самооценкой, но и будет изгнан на низший социальный уровень. Это, несомненно, ущемит его права на жизнь, владение имуществом, общение с другими людьми в обществе. Поэтому право на образование, по-видимому, не ограничивается школьным курсом, оно также распространяется на все неофициальные технические и другие виды обучения, которые позволяют людям приобретать необходимые навыки для достижения экономического блага.

5. Право на благоприятную окружающую среду. Решения судов других юрисдикций показывают, что право на здоровую окружающую среду интегрировано в право на жизнь. Действительно, важность здоровой и продуктивной среды для поддержания жизни и благополучия людей не подлежит сомнению. Ненадлежащие условия окружающей среды негативно отражаются на здоровье граждан, в частности существенно воздействуют на людей, которые занимаются рыболовством или фермерством для получения заработка. Кроме того, они оказывают серьезное отрицательное влияние на общее благосостояние того или иного государства, поскольку вредная окружающая среда ограничивает способность нации прокормить себя, а также истощает сельские общины из-за необходимости искать другие средства к существованию, иногда с помощью преступных действий. Неблагоприятная среда напрямую воздействует и на продолжительность жизни - сокращает ее.

В деле Мехта против Индии суд посчитал, что право на жизнь включает право жить в чистой и безопасной окружающей среде [17]. В деле Шела Зия против Водного хозяйства и развития энергетики Верховный суд Пакистана вынес аналогичное постановление [18]. Данные решения отражают тот фракт, что социально-экономические и экологические права не только обеспечивают надлежащий уровень жизни, но и помогают гарантировать условия, которые являются основополагающими для человеческого существования, без которых «фундаментальные права» не будут иметь никакого значения. Из этого следует, что сложные отношения между правом на здоровую окружающую среду и правом на жизнь не могут быть устранены путем умаления первого права до степени дискриминации.

В деле Фадеевой против Российской Федерации от 09.06.2005 г. основанием для обращения в Европейский суд по правам человека послужила деятельность сталеплавильного цеха «Северстали», представляющая опасность для жизни и здоровья истца [19]. Заявительница проживала в пределах санитарной зоны безопасности, но в соответствии с официальной статистикой 
в определенные годы было отмечено увеличение концентрации вредных веществ в воздухе, превышавшей допустимую норму. Суд пояснил, что заявительница не предоставила каких-либо доказательств по жалобе, в связи с чем она была признана неприемлемой.

Таким образом, право на жизнь включает в себя следующие элементы:

- право на охрану здоровья и медицинскую помощь;

- право на благоприятную окружающую среду, в том числе на безопасную питьевую воду;

- право на достаточный уровень и приемлемые условия жизни;

- право на образование;

- положительная обязанность государства по обеспечению условий, гарантирующих достойное качество жизни.

Доктринальные подходы и судебная практика в достаточной степени раскрывают составляющие права на жизнь, которые напрямую не закреплены в законодательстве упомянутых государств, но вытекают из толкования важнейшего права, т. е. права на жизнь.

\section{Ссылки:}

1. Концептуальные положения новой Конституции Республики, данные Институтом законодательства и сравнительного правоведения // Государство и право. 1992. № 8. С. 24.

2. Романовский Г.Б. Право на жизнь : монография. Архангельск, 2002. С. 5

3. Гражданское право : учебник / под ред. А.Г. Калпина, А.И. Масляева. М., 1997. Ч. І. С. 135-136.

4. Кутафин О.Е. Неприкосновенность в конституционном праве Российской Федерации. М., 2004. С. 241.

5. Танаев В.М. Право на смерть // Вестник Гуманитарного университета. Сер.: Право. 1999. № 1. С. 39.

6. Кальченко Н.В. Право человека на жизнь. Волгоград, 2003. С. 90.

7. Case of the "Street Children" (Villagran-Morales et al.) vs Guatemala [Электронный ресурс]. 1999. Nov., 19. URL: http://www.corteidh.or.cr/docs/casos/articulos/seriec_63_ing.pdf (дата об-ращения: 11.09.2017).

8. Osman vs United Kingdom [Электронный ресурc]. 1998. Oct., 28. URL: http://www.hrcr.org/safrica/life/Osman.html (дата обращения: 11.09.2017).

9. Paschim Banga Khet Mazdoor Samity vs State of West Bengal [Электронный pecypc]. URL: https://www.escrnet.org/caselaw/2006/paschim-banga-khet-mazdoor-samity-ors-v-state-west-bengal-anor-cited-1996-air-sc-2426 (дата обращения: 13.09.2017).

10. Конституция Индии [Электронный ресурс] // Конституции зарубежных государств : учебное пособие / coct. В.В. Маклаков. 4-е изд., перераб. и доп. М., 2003. URL: http://www.concourt.am/armenian/legal resources/world_constitutions/constit/india/india--r.htm (дата обращения: 11.09.2017).

11. Pentiacova and others vs Moldova [Электронный ресурc]. URL: http://www.globalhealthrights.org/health-topics/healthcare-and-health-services/pentiacova-and-ors-v-moldova/ (дата обращения: 11.09.2017).

12. Mahapatra D. Schools can't be allowed to fix exorbitant fees [Электронный ресурс] // The Times of India. 2010. Feb., 21 URL: http://timesofindia.indiatimes.com/india/Schools-cant-be-allowed-to-fix-exorbitant-fees/articleshow/5600370.cms (дата обращения: 11.09.2017).

13. Yakye Axa Indigenous Community vs Paraguay [Электронный ресypc]. URL: http://www.corteidh.or.cr/docs/casos/articulos/seriec_125_ing.pdf (дата обращения: 11.09.2017).

14. Case of the "Street Children" ...

15. Unni Krishnan J.P. vs State of Andhra Pradesh [Электронный ресурc]. 1993. Feb., 4. URL: https://www.escrnet.org/caselaw/2006/unni-krishnan-jp-ors-v-state-andhra-pradesh-ors-cited-1993-air-217-1993-scr-1-594-1993 (дата обращения: 11.09.2017).

16. Конституция Индии.

17. M.C. Mehta vs India [Электронный ресурс]. 1987. Sept., 22. URL: https://indiankanoon.org/doc/1208005 (дата обращения: 11.09.2017)

18. Ms. Shehla Zia vs WAPDA [Электронный ресурc]. 1994. Feb., 12. URL: https://www.ecolex.org/details/court-decision/msshehla-zia-and-others-petitioners-v-wapda-respondents-f12c9958-90c7-4dab-8c39-16290957624c (дата обращения: 11.09.2017)

19. Фадеева против России (Fadeyeva vs Russia) [Электронный ресурс] : постановление Европейского суда по правам человека от 9 июня 2005 г. : жалоба № 55723/00. URL: http://europeancourt.ru/resheniya-evropejskogo-suda-na-russkomyazyke/fadeeva-protiv-rossii-postanovlenie-evropejskogo-suda/ (дата обращения: 11.09.2017).

\section{References:}

Case of the "Street Children" (Villagran-Morales et al.) vs Guatemala 1999, November 19, viewed 11 September 2017, $<$ http://www.corteidh.or.cr/docs/casos/articulos/seriec_63_ing.pdf>.

'Conceptual provisions of the new Constitution of the Republic provided by the Institute of Legislation and Comparative Law under the Government of the Russian Federation' 1992, Gosudarstvo i pravo, no. 8, p. 24, (in Russian).

Fadeyeva vs. Russia: Judgment of the European Court of Human Rights as of 9 June 2005: Application no. 55723/00 2017, viewed 11 September 2017, <http://europeancourt.ru/resheniya-evropejskogo-suda-na-russkom-yazyke/fadeeva-protiv-rossiipostanovlenie-evropejskogo-suda/>, (in Russian).

Kalchenko, NV 2003, The human right to life, Volgograd, p. 90, (in Russian).

Kalpin, AG \& Maslyaev, Al (eds.) 1997, Civil law, textbook, Moscow, part I, pp. 135-136, (in Russian).

Kutafin, OE 2004, Inviolability in the constitutional law of the Russian Federation, Moscow, p. 241, (in Russian).

Mahapatra, D 2010, 'Schools can't be allowed to fix exorbitant fees', The Times of India, February 21, viewed 11 September 2017, <http://timesofindia.indiatimes.com/india/Schools-cant-be-allowed-to-fix-exorbitant-fees/articleshow/5600370.cms>

Maklakov, VV (comp.) 2003, 'Constitution of India', Konstitutsii zarubezhnykh gosudarstv: uchebnoye posobiye, 4th ed., Moscow, viewed 11 September 2017, <http://www.concourt.am/armenian/legal_resources/world_constitutions/constit/india/india- r.htm>, (in Russian). 
M.C. Mehta vs India 1987, September 22, viewed 11 September 2017, <https://indiankanoon.org/doc/1208005>.

Ms. Shehla Zia vs WAPDA 1994, February 12, viewed 11 September 2017, <https://www.ecolex.org/details/court-decision/ms-shehla-zia-and-others-petitioners-v-wapda-respondents-f12c9958-90c7-4dab-8c39-16290957624c>

Osman vs United Kingdom 1998, October 28, viewed 11 September 2017, <http://www.hrcr.org/safrica/life/Osman.html>.

Paschim Banga Khet Mazdoor Samity vs State of West Bengal 2017, viewed 13 September 2017, <https://www.escrnet.org/caselaw/2006/paschim-banga-khet-mazdoor-samity-ors-v-state-west-bengal-anor-cited-1996-air-sc-2426>.

Pentiacova and others vs Moldova 2017, viewed 11 September 2017, <http://www.globalhealthrights.org/health-topics/health-care-and-health-services/pentiacova-and-ors-v-moldova/>.

Romanovsky, GB 2002, The right to life, monograph, Arkhangelsk, p. 5, (in Russian).

Tanaev, VM 1999, 'The right to die', Vestnik Gumanitarnogo universiteta. Ser.: Pravo, no. 1, p. 39, (in Russian).

Unni Krishnan J.P. vs State of Andhra Pradesh 1993, February 4, viewed 11 September 2017, <https://www.escrnet.org/caselaw/2006/unni-krishnan-jp-ors-v-state-andhra-pradesh-ors-cited-1993-air-217-1993-scr-1-594-1993>.

Yakye Axa Indigenous Community vs Paraguay 2017, viewed 11 September 2017, <http://www.corteidh.or.cr/docs/casos/articulos/seriec_125_ing.pdf>. 